Research Paper

\title{
Aqueous Ocimum gratissimum extract induces cell apoptosis in human hepatocellular carcinoma cells
}

\author{
Chen-Cheng Huang1,2, Jin-Ming Hwang 3 , Jen-Hsiang Tsai ${ }^{4}$, Jing Huei Chen ${ }^{5}$, Ho Lin', Geng-Jhih Lin', \\ Hsin-Ling Yang7, Jer-Yuh Liu ${ }^{5,8}{ }^{\bowtie}$, Chiou-Ying Yang ${ }^{\circledR}$, Je-Chiuan Ye ${ }^{9,10^{\bowtie}}$ \\ 1. Institute of Molecular Biology College of Life Science, National Chung Hsing University, Taichung, Taiwan \\ 2. Division of Chest Medicine, Department of Internal Medicine, Taichung Hospital, Ministry of Health and Welfare, Taichung, Taiwan \\ 3. School of Applied Chemistry, Chung-Shan Medical University, Taichung 40201, Taiwan \\ 4. Basic Medical Science Education Center, College of Medicine and Health, Fooyin University, Kaohsiung, Taiwan \\ 5. Graduate Institute of Biomedical Sciences, China Medical University, Taichung, Taiwan \\ 6. Department of Life Science, National Chung Hsing University, Taichung, Taiwan \\ 7. Institute of Nutrition, College of Biopharmaceutical and Food Sciences, China Medical University, Taichung, Taiwan \\ 8. Center for Molecular Medicine, China Medical University Hospital, Taichung, Taiwan \\ 9. Department of Bachelor's Degree Program for Indigenous Peoples in Senior Health and Care Management, National Taitung University, Taitung, Taiwan \\ 10. Master Program in Biomedical Science, National Taitung University, Taitung, Taiwan
}

$\square$ Corresponding authors: Jer-Yuh Liu, PhD, Graduate Institute of Biomedical Sciences, College of Medical, China Medical University, No 91, Hsueh-Shih Road, Taichung 40402, Taiwan. Tel: +886-4-22052121 ext 7932; Fax: +886-4-22347028. E-mail: jyl@mail.cmu.edu.tw. Chiou-Ying Yang PhD., Institute of Molecular Biology, College of Life Science, National Chung Hsing University No.145 Xingda Rd., South Dist., Taichung 402, Taiwan. Tel: +886-4-22840485 ext. 241; E-mail: cyyang@dragon.nchu.edu.tw. Je-Chiuan Ye PhD., Department of Bachelor's Degree Program for Indigenous Peoples in Senior Health and Care Management, National Taitung University, No.369, Sec. 2, University Road, Taitung City, Taitung County 950, Taiwan. Tel: +886-89-513885; e-mail: 9503023@gmail.com.

(c) The author(s). This is an open access article distributed under the terms of the Creative Commons Attribution License (https://creativecommons.org/licenses/by/4.0/). See http://ivyspring.com/terms for full terms and conditions.

Received: 2019.08.18; Accepted: 2019.11.10; Published: 2020.01.18

\begin{abstract}
Treatment of advanced hepatocellular carcinoma $(\mathrm{HCC})$ has exhibited a poor overall survival rate of only six to ten months, and the urgency of the development of more effective novel agents is ever present. In this line of research, we aimed to investigate the effects and inhibitive mechanisms of aqueous Ocimum gratissimum leaf extract (OGE), the extract of Ocimum gratissimum, which is commonly used as a therapeutic herb for its numerous pharmacological properties, on malignant HCC cells. Our results showed that OGE decreased the cell viability of HCC SK-Hepl and HA22T cells in a dose-dependent manner (from 400 to $800 \mu \mathrm{g} / \mathrm{mL}$ ), while there is little effect on Chang liver cells. Moreover, cell-cycle analysis shows increased Sub-Gl cell count in SK-Hepl and HA22T cells which is not observed in Chang liver cells. These findings raise suspicion that the OGE-induced cell death may be mediated through proteins that regulate cell cycle and apoptosis in SK-Hepl and HA22T cells, and further experimentation revealed that OGE treatment resulted in a dose-dependent decrease in caspase 3 and PARP expressions and in CDK4and p-ERK1/2expressions. Moreover, animal tests also exhibited decreased HCC tumor growth by OGE treatment. We therefore suggest that the inhibition of cell viability and tumor growth induced by OGE may be correlated to the alteration of apoptosis-related proteins.
\end{abstract}

Key words: Ocimum gratissimum, hepatocellular carcinoma, cell cycle arrest

\section{Introduction}

Hepatocellular carcinoma (HCC) is the fifth most common cancer type and the third leading cause of cancer-related death around the world [1-3], accounting for $75 \%$ to $85 \%$ of all primary liver cancer cases [4]. The therapeutic approach for HCC depends on disease staging. Patients with early stage HCC are candidates for surgical resection, or radical therapy (cryosurgery, liver transplantation or local ablation via percutaneous ethanol injection (PEI) or radiofrequency ablation (RFA) with 5-year survival rates of $41-74 \%$ [5]. For intermediate stage HCC, patients benefit from hepatic artery chemoembolization (TACE). However, patients with advanced HCC have very poor prognosis with an overall survival of only 6.5 to 10.7 months from sorafenib treatment [6-9]. Therefore, the development of an effective novel 
agents with reduced toxicity is a priority to improve survival for advanced HCC.

Ocimum gratissimum is a commonly used herbal ingredient in traditional Chinese medicine and is widely distributed in tropical and warm temperate geo-locations. O. gratissimum aqueous extracts (OGE) with its many antioxidant components, has the potential to protect body organs from free radical damage and oxidative stress [10-19], and possesses many therapeutic functions, including anti-inflammation [20], analgesic and spasmolytic activities [21], antidiarrheal [22], antiviral [23] and anti-hyperglycemic activities [24, 25], and improves phagocytic function without affecting the humoral or cellmediated immune system [26]. In anti-cancer activity, the data have found that OGE can induce cell apoptosis in human lung adenocarcinoma A549 cells [27] and human osteosarcoma U2-OS and HOS cells [28]. It is also able to modulate some cell cycle regulators (SKA2 and BUB1B) and apoptosis-related factors (PPP1R15A, SQSTM1, HSPA1B and DDIT4), which are reported to associate with drug resistance $[29,30]$. Moreover, in breast cancer, OGE inhibits cell chemotaxis and chemo-invasion in vitro and retards tumor growth and temporal progression in vivo [31]. In prostate cancer [32], OGE inhibits cancer cell growth through reducing androgen receptor and survivin protein in a time dependent manner.

This study intends to investigate the cytotoxic and therapeutic effect of OGE on liver cancer cells, and the results showing that OGE can induce cell apoptosis and reduce tumor growth in HCC cells are discussed.

\section{Methods and Materials}

\section{Materials}

3-(4,5-dimethylthiazol-2-yl)-2,5-diphenyl-tetrazo lium bromide (MTT), penicillin and streptomycin were purchased from Sigma (St. Louis, MO). Dulbecco's modified Eagle's medium (DMEM), fetal bovine serum (FBS) and trypsin-EDTA were purchased from Gibco BRL (Gaithersburg, MD). Antibodies against caspase 3, PARP, cyclindependent kinase 4 (CDK4), cyclin-dependent kinase 2 (CDK2), PFKFB3 and phospho-extracellular signalregulated kinase1/2 (p-ERK1/2) were purchased from Cell Signaling Technologies (Beverly, MA). Antibodies against $\beta$-actin were obtained from Sigma. HRP-conjugated secondary antibodies against mouse IgG and rabbit IgG were purchased from Abcam Inc. (Cambridge, UK). The human hepatocellular carcinomaSK-Hep1 andHA22T cells, and one normal liver cell line (Chang-liver) were obtained from American Type Culture Collection (ATCC; Rockville,
MD).The Mahlavu cells were gifted by Dr. Jaw-Ching $\mathrm{Wu}$ from the Institute of Clinical Medicine of the National Yang Ming University. The HA22T/VGH and SK-Hep-1 lines are malignant [33,34].

\section{Preparation of $O$. gratissimum extract}

Leaves of OG were harvested and washed with distilled water followed by homogenization with distilled water using a Polytron homogenizer. The homogenate was boiled for $1 \mathrm{~h}$ and then filtered through two layers of gauze. The filtrate was centrifuged at 20,000 g at $4^{\circ} \mathrm{C}$ for $15 \mathrm{~min}$ to remove insoluble pellets and the supernatant (OGE) was thereafter collected, lyophilized and stored at $-70^{\circ} \mathrm{C}$ until use.

\section{Cell Culture and Experimental Treatments}

All cells were cultured in DMEM or RPMI 1640and supplemented with $10 \%$ FBS and $100 \mu \mathrm{g} / \mathrm{mL}$ penicillin/streptomycin at $37^{\circ} \mathrm{C}$ in a humidified atmosphere containing $5 \% \mathrm{CO}_{2}$. The HCC cells were maintained in $100 \mu \mathrm{M}$ non-essential amino acid, $2 \mathrm{mM}$ glutamate. Cells were seeded in culture plates and grown to approximately $80 \%$ confluence. Cells (4x $10^{4} \mathrm{cells} / \mathrm{mL}$ ) were then transported to experiment culture plates and maintained at $37^{\circ} \mathrm{C}$ in a humidified atmosphere containing $5 \% \mathrm{CO}_{2}$. After $48 \mathrm{~h}$, the cells were treated with OGE at indicated concentrations for the indicated hours and then collected for the following analyses.

\section{MTT Assay for Cell Viability}

Cell viability was determined by MTT assay after treatment of the cells with $0,100,200,400,600$ and 800 $\mu \mathrm{g} / \mathrm{mL}$ OGE for 24,48 and $72 \mathrm{~h}$. After the treatments, medium was removed, and cells were incubated with MTT(3-(4,5-Dimethylthiazol-2-yl)-2,5-diphenyltetrazo lium bromide) $(0.5 \mathrm{mg} / \mathrm{mL})$ at $37^{\circ} \mathrm{C}$ for $2 \mathrm{~h}$. The viable cell number was directly proportional to the production of formazan, which was dissolved in isopropanol and determined by measuring the absorbance at 570nm using a microplate reader (Spectra MAX 360 pc, Molecular Devices, Sunnyvale, CA).

\section{Cell Cycle Analysis by Flow Cytometry}

The cell cycle was analyzed by flow cytometry after treatment of the cells with $0,400,600$ and 800 $\mu \mathrm{g} / \mathrm{mL}$ OGE for $48 \mathrm{~h}$. All of the cells, cells in the suspension and adherent cells, were collected, washed, and suspended in cold PBS. Cells were then fixed in chilled $75 \%$ methanol and stained with propidium iodide (PI). Analysis was performed in the FACSCalibur flow cytometer running CellQuest (Becton Dickinson, San Jose, CA).

\section{Western Blotting Analysis}

Cells were washed with PBS and lysed with lysis 
buffer $(50 \mathrm{mM}$ Tris- $\mathrm{HCl}, \mathrm{pH} 7.5,150 \mathrm{mM} \mathrm{NaCl}, 1 \%$ Nonidet P-40, $1 \mathrm{mM}$ phenylmethylsulfonyl fluoride, $1 \mathrm{mM}$ sodium fluoride, and $10 \mu \mathrm{g} / \mathrm{mL}$ aprotinin and leupeptin) after treatment of the cells with0, 400, 600, $800 \mu \mathrm{g} / \mathrm{mL}$ OGE for $24 \mathrm{~h}$. The lysates were put on ice for $30 \mathrm{~min}$ and then centrifuged at 20,000 $\mathrm{g}$ for $15 \mathrm{~min}$. The supernatants were collected and measured for protein concentration using the Bradford method. Crude proteins (30 $\mathrm{\mu g}$ per lane) were subjected to a $12.5 \%$ SDS-polyacrylamide gel, and then transferred onto a nitrocellulose membrane (Millipore, Bedford, MA). The blotted membrane was then blocked with $5 \% \mathrm{w} / \mathrm{v}$ skimmed milk in PBS, and then incubated for $2 \mathrm{~h}$ with 1/1000 dilution of antibodies against human Caspase 3, PARP, p-ERK1/2, CDK4, CDK2, PFKFB3, and $\beta$-actin. $\beta$-Actin protein was used as an internal control. Antigen-antibody complex was detected using 1/2000 dilution of peroxidase-conjugated secondary antibodies and displayed using ECL chemiluminescence reagent (Millipore, Bedford, MA).

\section{Bioenergetic assay}

Analysis of oxygen consumption rate (OCR) and extracellular acidification rate (ECAR) were performed using a Seahorse XFe Flux Analyzer (Seahorse Bioscience). SK-Hep1 cells were seeded into XF 24-well cell culture microplates with serum-free DMEM in Extracellular Flux (XF) media (nonbuffered RPMI 1640 containing $25 \mathrm{mM}$ glucose, $2 \mathrm{mM}$ L-glutamine and $1 \mathrm{mM}$ sodium pyruvate). Cells were then transferred to a $\mathrm{CO}_{2}$ free incubator, maintained at $37^{\circ} \mathrm{C}$ in a humidified atmosphere overnight. The SK-Hep1 cells were then treated with 0, 200, 400, 600 $\mu \mathrm{g} / \mathrm{mL}$ OGE immediately before the assay. Following instrument calibration, the OGE treated cells were transferred to the XFe Flux Analyzer to record OCR and ECAR in 200, 400, 600 minutes.

\section{Tumorigenicity Assay in Nude Mice}

Female BALB/c nude mice, 4-6 weeks of age, are purchased from National Health Research Institute (Taipei, Taiwan, ROC), housed in a dedicated nude mouse facility with microisolator caging. The Mahlavu cells are detached by trypsinisation $48 \mathrm{~h}$ later, and then washed in triplicate in serum-free DMEM. $1 \times 10^{7}$ cells in $20 \mu \mathrm{l}$ volume is injected into the liver organ of mice by use of a $0.3 \mathrm{ml}$ insulin syringe with 29-gauge needle. Two weeks after injection, the mice are separated into control (water)-and60mg/kg OGE-oral-injected groups. There are 2-3 mice in each group. One month after treatment, the tumors and organs were harvested from the sacrificed mice and weighed.

\section{Statistical Analysis}

Data were expressed as mean \pm SEM and analyzed using analysis of variance (ANOVA). Student's t-test was used in two-group comparisons. $\mathrm{P}<0.05$ was considered to be statistically significant.

\section{Results}

\section{OGE Inhibits cell viability of HCC cells}

To examine the cytotoxic effects of OGE on the HCC cells and the Chang liver cells, they were treated with serial concentrations of OGE $(0,100,200,400,600$, $800 \mu \mathrm{g} / \mathrm{mL}$ ) for0, 24,48 and $72 \mathrm{~h}$ and subsequently analyzed for cell viability by using MTT assays (Figure 1). In SK-Hep1 and HA22T cells, cell viability significantly decreased compared to control when OGE concentration was above $200 \mu \mathrm{g} / \mathrm{mL}$ at 48 and 72 h (Figure 1). There was no statistically significant change of cell viability observed on the Chang liver cells below $800 \mu \mathrm{g} / \mathrm{mL}$ at $72 \mathrm{~h}$.

\section{Chang liver}
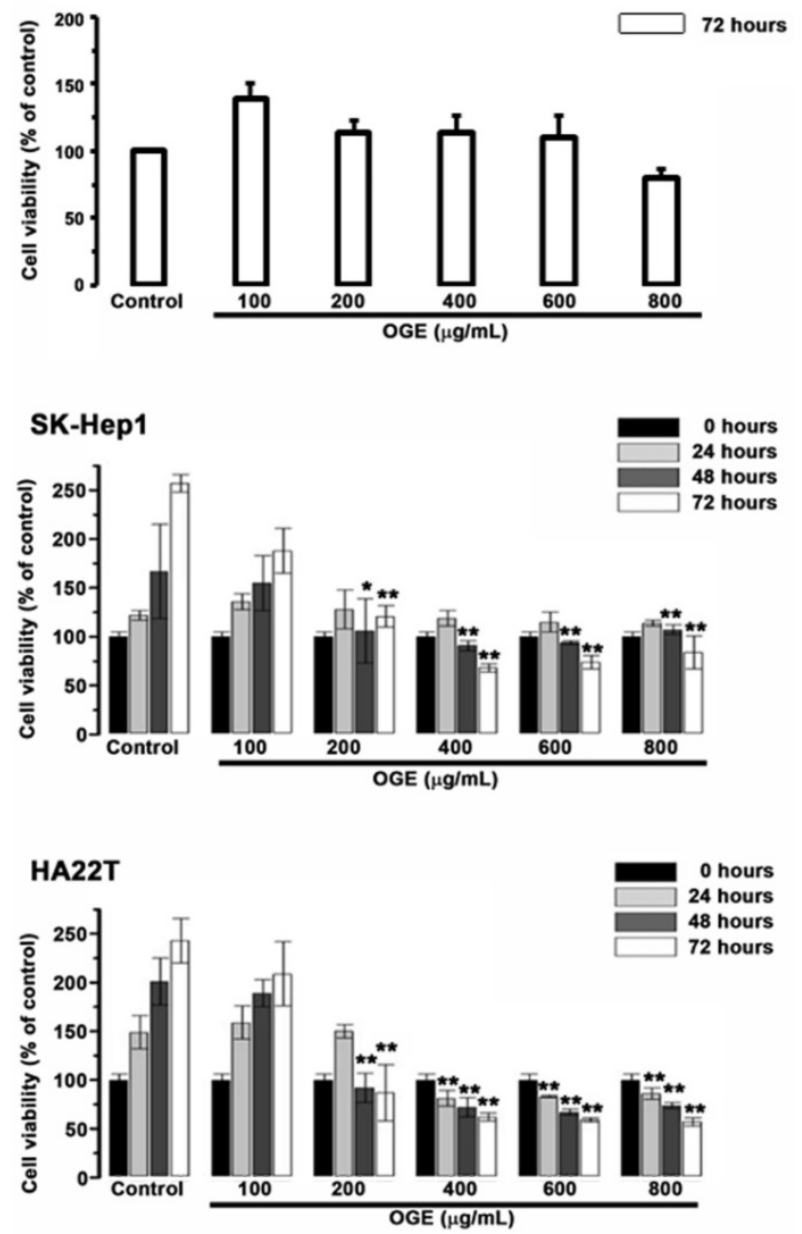

Figure 1. Effects of OGE on the viability of the Chang liver, SK-Hepl and HA22T cells. Cell growth was determined 24,48 , and $72 \mathrm{~h}$ after OGE treatment using the MTT assay as described in the Materials and Methods. Absorbance values obtained from the cells on hour 0 of treatment on subculture were taken as $100 \%$. The data indicate mean \pm SE $\left(n=3\right.$ in each group). ${ }^{* *} p<0.01,{ }^{*} p<0.05$ as compared with control $0 \mu \mathrm{g} / \mathrm{mL}$ OGE group. 
OGE induces morphological alteration in HCC cells

To observe the cell morphology, the HCC cells treated with different concentrations $(0,200,400,600$, $800 \mu \mathrm{g} / \mathrm{mL}$ ) of OGE were examined at $48 \mathrm{~h}$ using Nikon Digital Sight DS-L1(Figure 2). Cell Shrinkage and detachment were observed on the SK-Hep1 and HA22T cells in a dose-dependent manner. No morphology change was detected in OGE-treated Chang liver cells.

\section{OGE changes cell cycle in HCC cells}

To investigate the effects of OGE on cell cycle, cells treated with different concentration of OGE
$(0,400,600,800 \mu \mathrm{g} / \mathrm{mL})$ for $48 \mathrm{~h}$ were collected for cell cycle analysis using BD FACSCalibur Flow Cytometer. The results showed that the cell number in sub-G1 phase in SK-Hep1 cells was significantly increased by $47 \%, 92 \%$, and $178 \%$ compared to 0 dose control group in 400, 600 and $800 \mu \mathrm{g} / \mathrm{mL}$ of OGE respectively (Figure 3), and in HA22Tcells was significantly increased by $18 \%, 283 \%$, and $489 \%$ compared to 0 dose control group in 400, 600 and 800 $\mu \mathrm{g} / \mathrm{mL}$ of OGE respectively, while the cell number in the rest of the cell cycle phases were relatively decreased, indicating a certain level of cell death. Whereas, no significant change was observed in Chang liver cells.

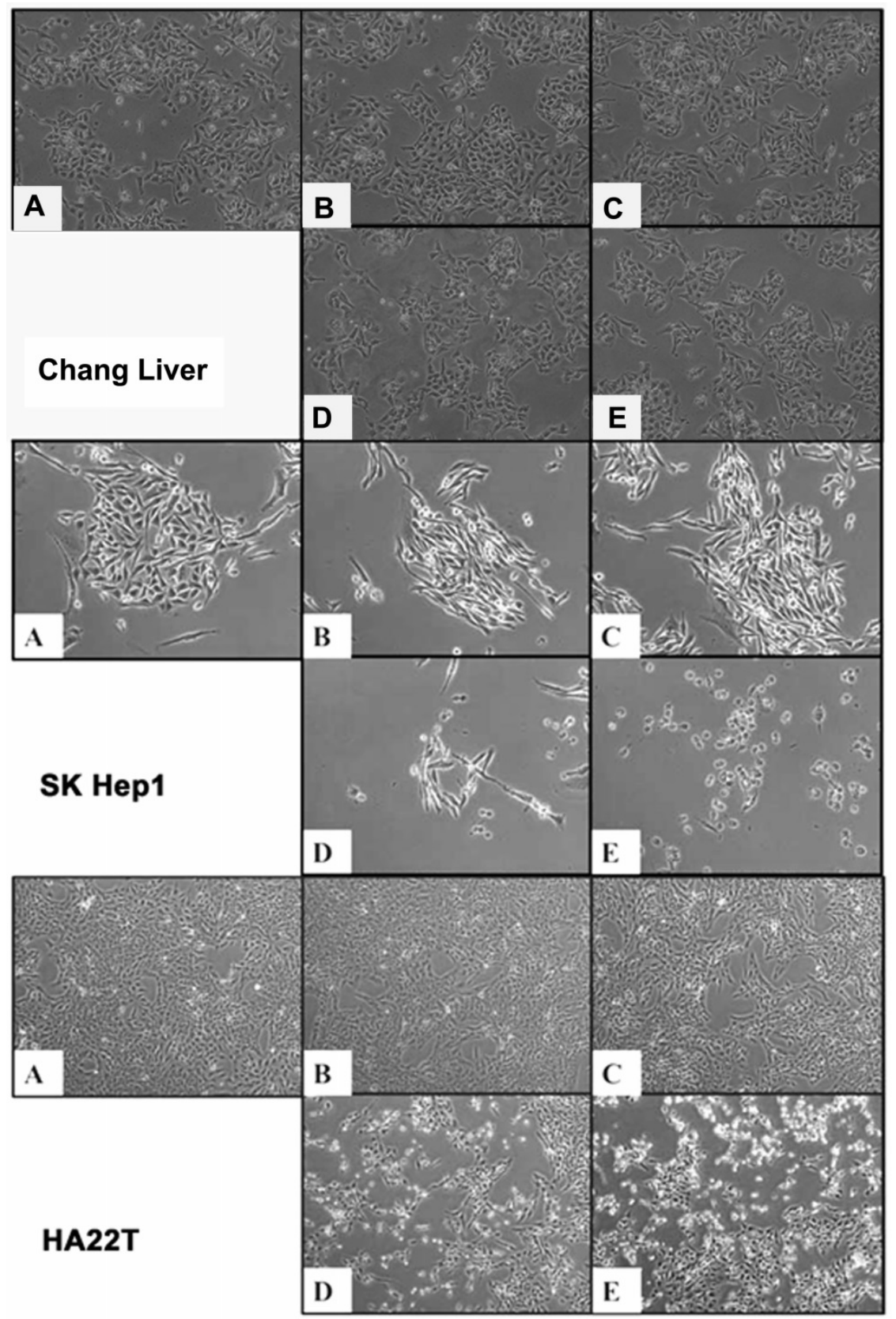

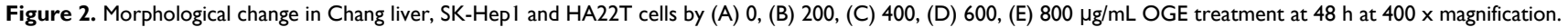




\section{Chang liver}
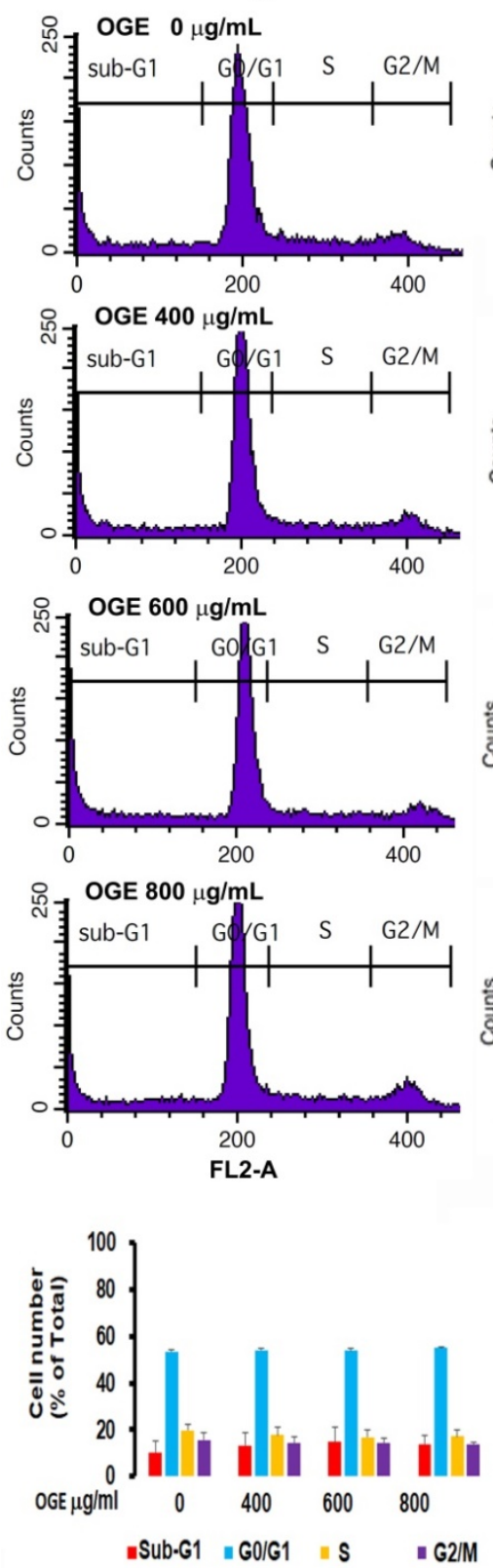

SK-Hep1

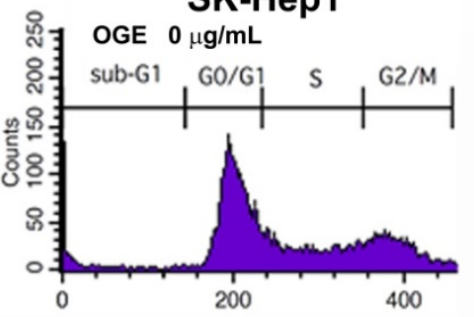

OGE $400 \mu \mathrm{g} / \mathrm{mL}$
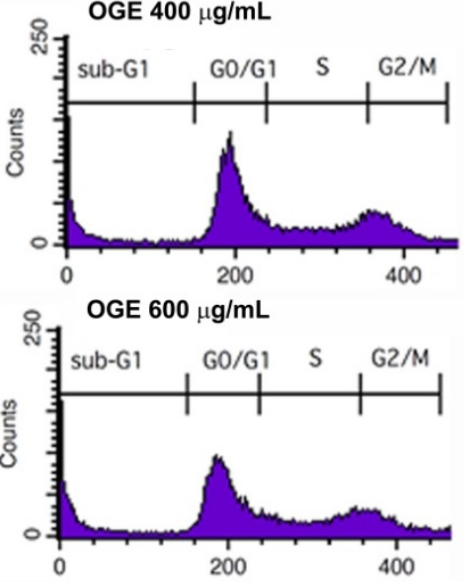

OGE $800 \mu \mathrm{g} / \mathrm{mL}$
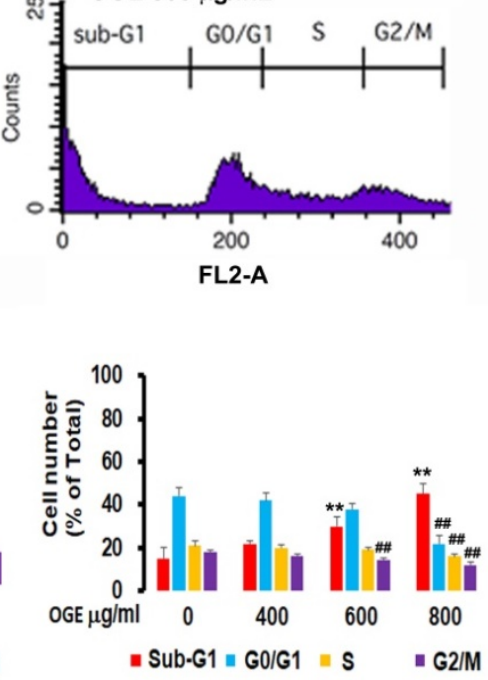

HA22T
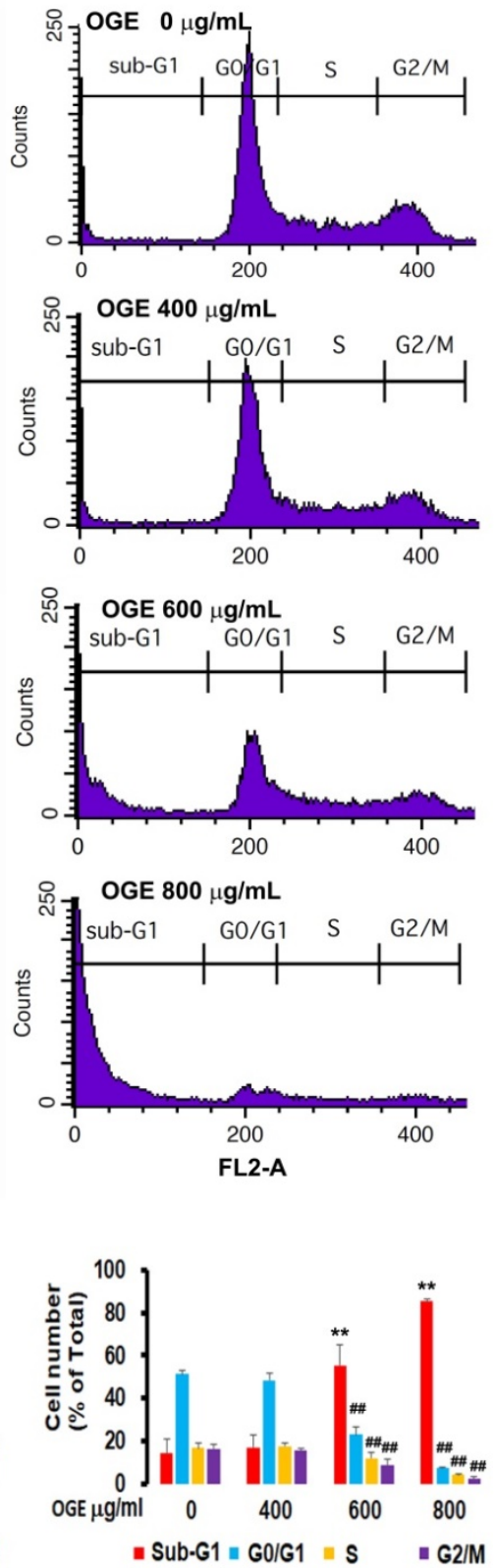

Figure 3. Cell cycle distribution by flow cytometry analysis in Chang liver, SK-Hepland HA22Tcells after exposure to OGE. The cells were treated with 0 , 400,600 , and 800 $\mu \mathrm{g} / \mathrm{mL}$ OGE for $48 \mathrm{~h}$. Results are plotted as the percentage of remaining cells in each cell cycle phase. Data is presented as mean $\pm \mathrm{SE}$ of three independent experiments. The data indicate mean \pm SE ( $n=3$ in each group). ${ }^{* *} p<0.01$ up-regulation as compared with control group; $\mathrm{m}<0.01$ down-regulation as compared with control group.

OGE changes the expressions of the cell-apoptosis- and cell-cycle-related checkpoint proteins in HCC cells.

To determine whether OGE could affect cell apoptosis-related proteins, we examined the expressions of caspase 3 and PARP by immunoblotting in HCC cells after treatment with different concentrations $(0,400$, and $600 \mu \mathrm{g} / \mathrm{mL})$ of OGE for 24 h. In SK-Hep1 and HA22T cells, PARP and caspase 3 levels decreased (Figure 4) in the treatment of 600 $\mu \mathrm{g} / \mathrm{mL}$ of OGE. Whereas, no significant change was observed in Chang liver cells in the above concentrations.

To determine whether OGE could affect cell cycle related checkpoint proteins, we further examined the expressions of CDK4, CDK2, p-ERK1/2, and PFKFB3 by immunoblotting in HCC cells after treatment with different concentrations $(0,400$, and $600 \mu \mathrm{g} / \mathrm{mL}$ ) of OGE for $24 \mathrm{~h}$. In SK-Hep1 and HA22T cells, the protein levels of CDK4, p-ERK1/2, and PFKFB3decreased (Figure 5). No change was observed in CDK2 levels in either cells, and no significant change in all checkpoint proteins was observed in Chang liver cells. 

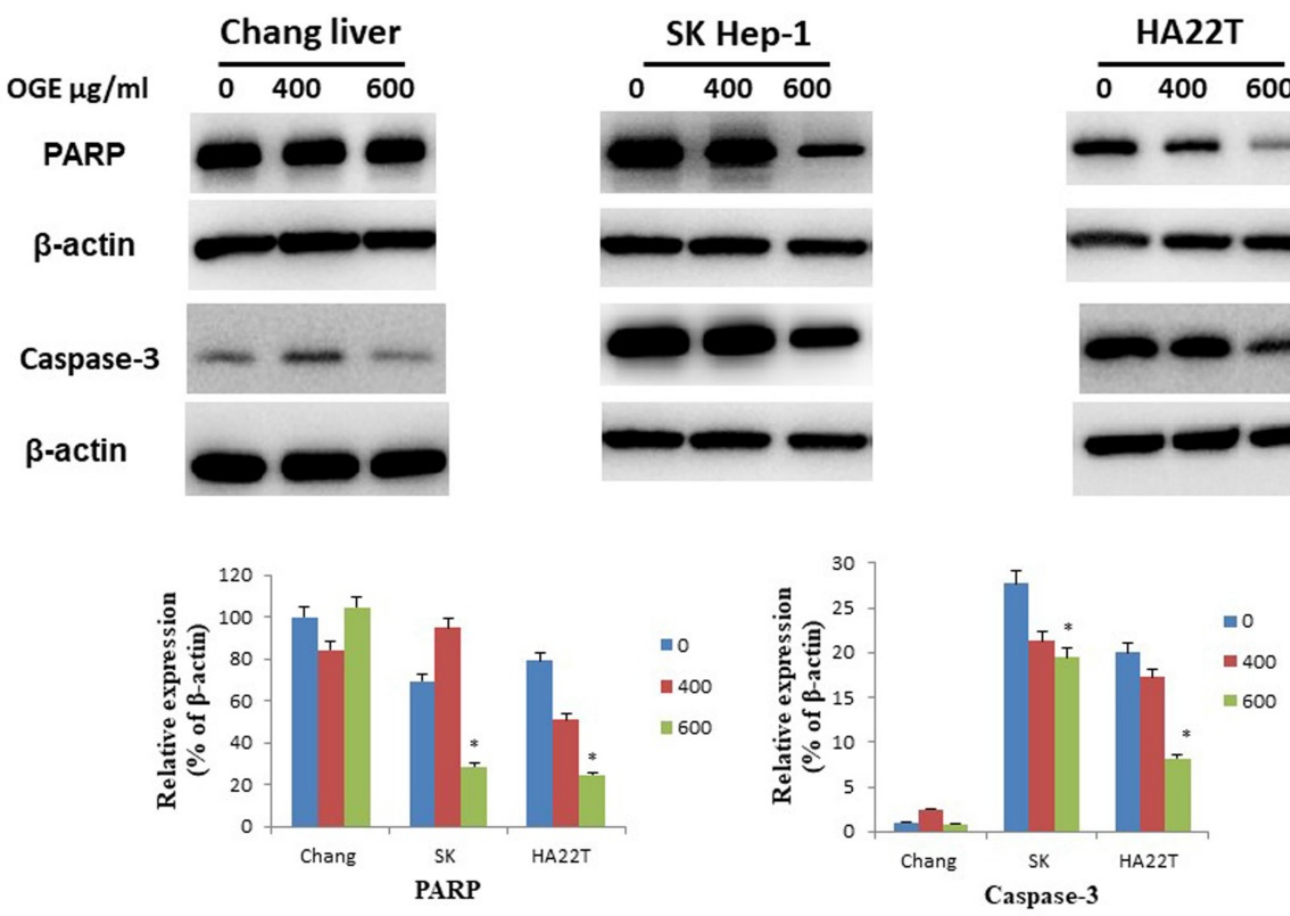

Figure 4. Expression of caspase 3and PARP in Chang liver, SK-Hepl and HA22T cells measured by immunoblotting analysis. Cells were treated with 0,400 , and $600 \mu g / m L ~ O G E$ for $24 \mathrm{~h}$. Immunoblotting analysis were performed as described in the Materials and Methods. Control cells (treated with $0 \mu \mathrm{g} / \mathrm{mL} \mathrm{OGE)} \mathrm{were} \mathrm{treated} \mathrm{with} \mathrm{vehicle} \mathrm{alone.} \mathrm{The} \mathrm{data}$ indicate mean \pm SE ( $n=3$ in each group). ${ }^{*} \mathrm{p}<0.05$ down-regulation as compared with control group.
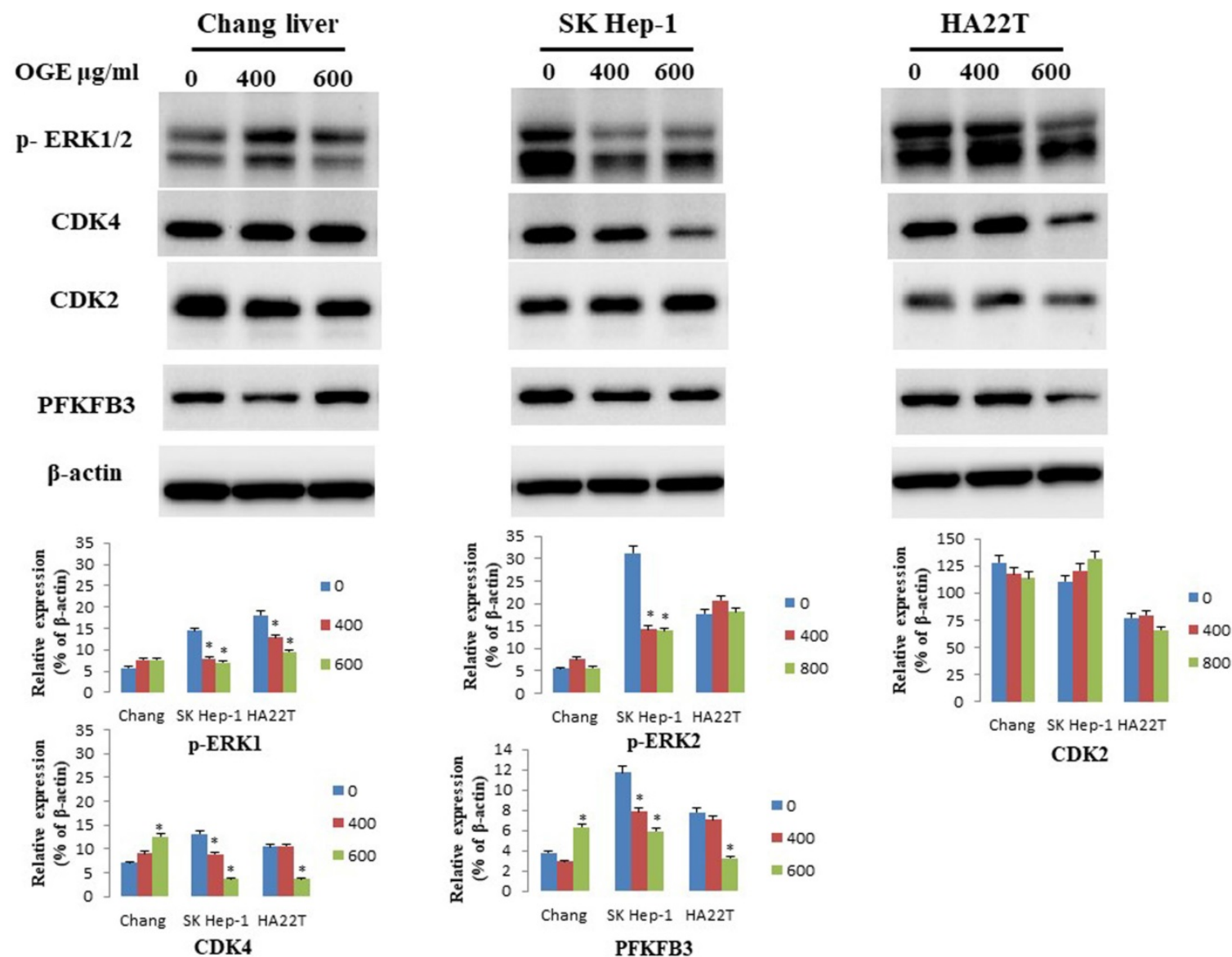

Figure 5. Expression of CDK4, CDK2,p-ERK1/2 and PFKFB3in Chang liver, SK-Hepl and HA22T cells measured by immunoblotting analysis. Cells were treated with 0 , 400, and $600 \mu \mathrm{g} / \mathrm{mL}$ OGE for $24 \mathrm{~h}$. Immunoblotting analysis were performed as described in the Materials and Methods. Control cells (treated with $0 \mu \mathrm{g} / \mathrm{mL}$ OGE) were treated with vehicle alone. The data indicate mean $\pm \mathrm{SE}\left(n=3\right.$ in each group). ${ }^{*} \mathrm{p}<0.05$ down-regulation as compared with control group. 


\section{OGE significantly decreases ECAR of glycolysis in HCC cells}

It is known that malignant cells such as HCC cells prefer to consume energy from the process of aerobic glycolysis but not from mitochondria function [35]. CDK4 has been identified as oncogenic when alongside other genes, such as ERK, c-Myc, and cyclin D1, and participates in the glycolytic process [36, 37]. CDK4 itself was found to promote glycolysis [38] and potentially acts as a positive clinical prognostic marker for malignant phenotypes of HCC [39]. In the above data, OGE has been observed to inhibit CDK4, and we hypothesized that OGE can affect the glycolytic process through this pathway and not the mitochondria pathway.

To investigate whether OGE reduces cell viability through inhibiting glycolysis or mitochondrial function, ECAR and OCR were analyzed using a Seahorse XFe Flux AnalyzeronSK-Hep1 cells at OGE concentrations of $0,200,400$ and $600 \mu \mathrm{g} / \mathrm{mL}$ at the indicated timeframes. ECAR was significantly decreased by $88 \%, 116 \%$, and $129 \%$ compared to control group at 200 minutes, by $96 \%, 131 \%$, and $140 \%$ at 400 minutes, and by $116 \%, 142 \%$, and $151 \%$ respectively at 600 minutes (Figure 6). Whereas, OCR was significantly decreased by $65 \%, 90 \%$ and $93 \%$ compared to control group only in $600 \mu \mathrm{g} / \mathrm{mL}$ of OGE for 200, 400 and 600 minutes respectively. This suggests the effect of OGE on the glycolytic process over the mitochondrial function.
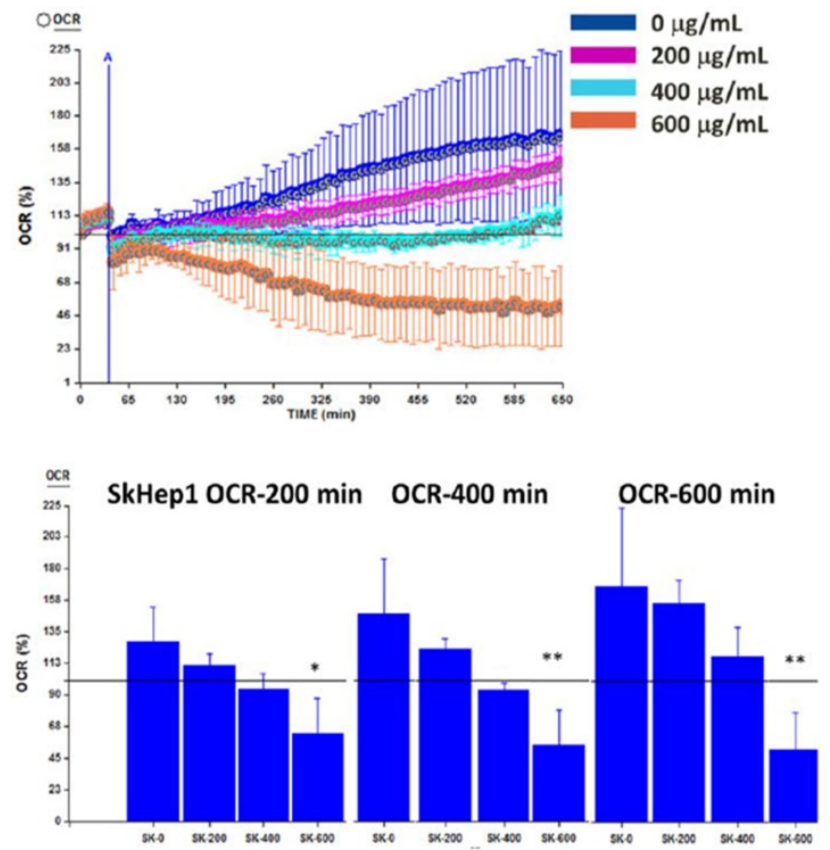

\section{OGE significantly decreases tumor growth}

To evaluate the therapeutic effects of OGE, nude mice bearing Mahlavu cell xenografts were orally injected with $60 \mathrm{mg} / \mathrm{kg}$ OGE daily for one month. As shown in Figure 7, compared with the tumor size in the control group, OGE-treated mice had smaller tumor sizes (Figure 7, upper panel). The mean weight of tumors of the control group was $3.1 \pm 2.2 \mathrm{~g}$ and $0.5 \pm 0.2 \mathrm{~g}$ for the OGE group, demonstrating that OGE significantly suppressed tumor weight compared to the control group. The spleen weight was decreased (Figure 7, middle panel) and the other organs showed no change in weight (figure 7 , bottom panel).

\section{Discussion}

Previously, OGE was reported to have cytotoxic effect on several human solid tumor cell lines including human lung, breast, cervical, bone and prostate cancers [40]. This study showed that OGE also had cytotoxic effect on HCC SK-Hep1and HA22T cells with morphological alterations and condensation changes and in a time- and dose-dependent manner. These findings are consistent with the results of cell-cycle and Western blot analyses, and those of our other studies [27, 28] which show that OGE significantly and dose-dependently modulate the expression of apoptosis-related proteins of cancer cells, indicating the activation of cell apoptosis. However, cytotoxic activity was absent on Chang liver cells, suggesting the selectivity of OGE on specific properties of cancer cells.

Figure 6. Oxygen consumption rate (OCR) and Extracellular acidification rate (ECAR) in SK-Hepl cells measured by Bioenergetic assay.SK-Hepl cells were treated with 0 , 200, 400 , and $600 \mu \mathrm{g} / \mathrm{mL}$ OGE for $600 \mathrm{mins}$. Bioenergetic assay were performed as described in the Materials and Methods. Control cells (treated with $0 \mu \mathrm{g} / \mathrm{mL} O \mathrm{OGE}$ ) were treated with vehicle alone. The data indicate mean \pm SE ( $n=3$ in each group). ${ }^{*} \mathrm{p}<0.01,{ }^{*} \mathrm{p}<0.05$ as compared with control $0 \mu \mathrm{g} / \mathrm{mL}$ OGE group. 

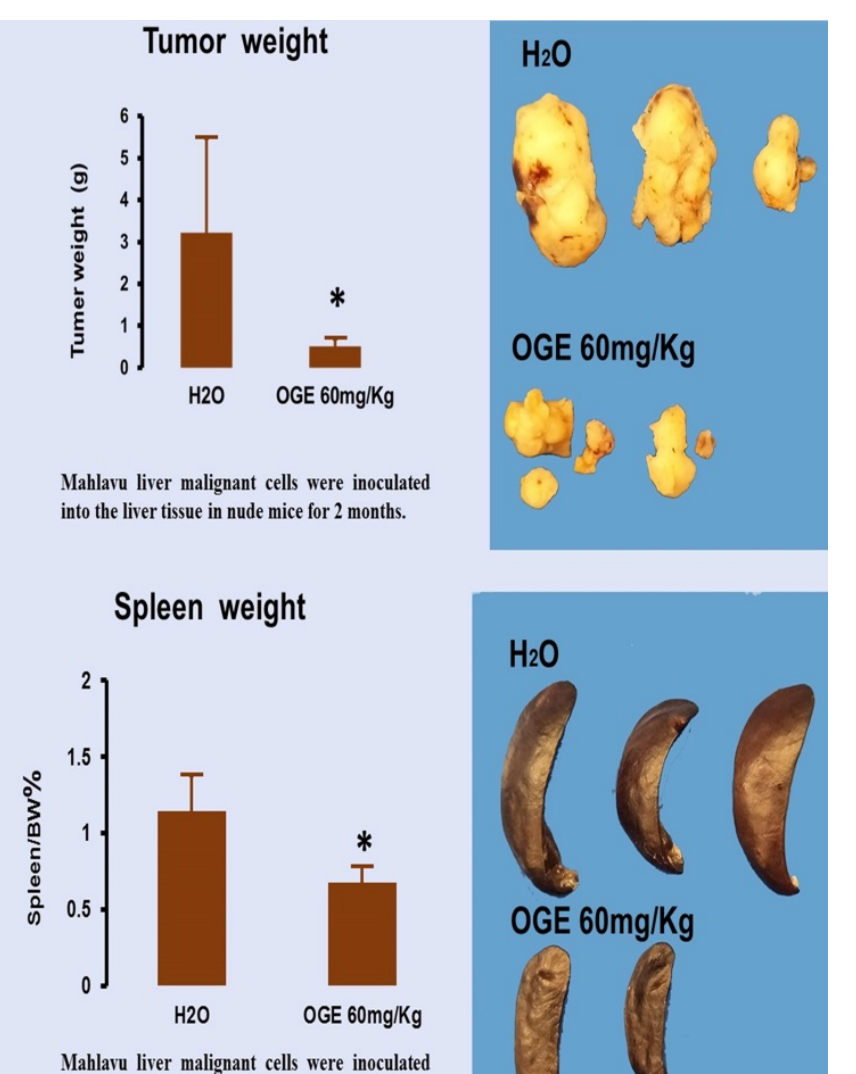
into the liver tissue in nude mice for 2 months.
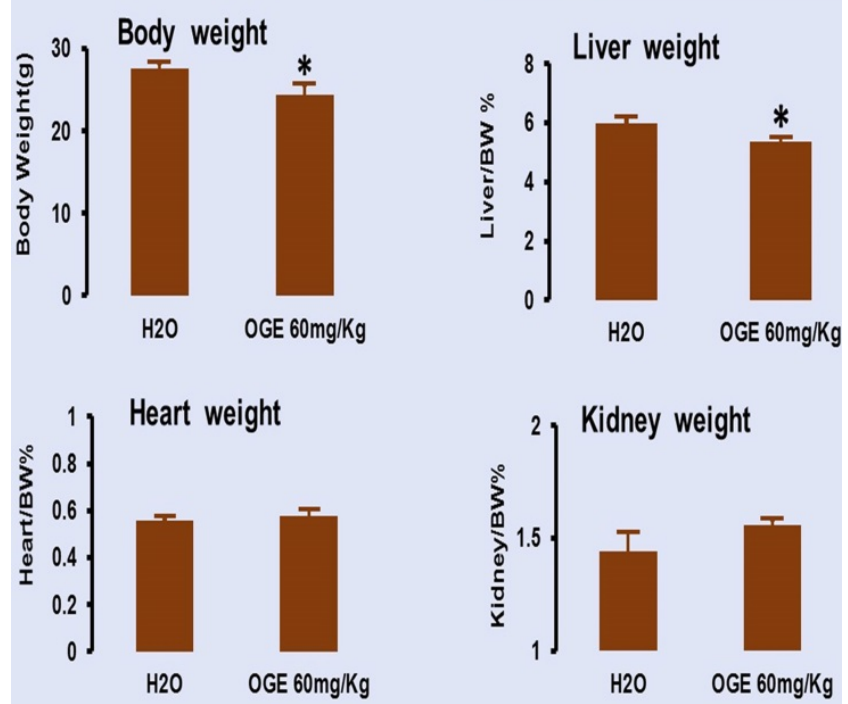

Figure 7. Tumor growth in nude mice after xenografts of hepatocellular carcinoma Mahlavu cells. Cancer removed from the mice were weighed (upper panel) and other organs removed from the same mice were weigh (middle and bottom panels). ${ }^{* *} p<$ 0.01 compared with control group.

Numerous human cancers, including liver cancer, are known to feature aberrant extracellular signal-regulated kinase (ERK) expressions [41], and ERK is known alongside numerous protein kinases, such as c-Jun N-terminal kinase (JNK), andp38 MAP kinase (p38), to make up the core of mitogen-activated protein (MAP) kinase pathway cascades. In HCC tissues, increased expression of ERK was correlated with poor disease-specific overall survival [42], which maybe a contributing factor to the malignancy and high frequency of metastasis of liver cancer. In this study we found decreased p-ERK1/2 levels in the HCC cells after OGE treatment, suggesting the influence of OGE on survival signaling of liver cancer cells with high ERK activity through an unknown mechanism.

The mechanism suspected to connect high ERK activity to survival signaling is aerobic glycolysis, which is promoted when ERK1/2 phosphorylates pyruvate kinase muscle isozyme (PKM1/M2) that translocate into the nucleus and upregulates the expressions of c-Myc, cyclin D1 and CDK4, which also promote cell viability [44]. The existence of a link between aerobic glycolysis and tumorigenesis has been known for several decades as the "Warburg effect" [45]. Cancer cells have a unique metabolism of performing lactic acid fermentation in the presence of oxygen. Since higher glycolytic rate in tumor cells can promote resistance to chemotherapeutics [46, 47], the interruption or even disruption of tumor glycolysis can impact tumor growth by energy depletion as well as sensitization to therapeutics. Moreover, CDK4 has been identified as oncogenic when alongside other genes and participates in the glycolytic process [48], and CDK4 itself was found to promote glycolysis [38] and potentially acts as a positive clinical prognostic marker for malignant phenotypes of HCC [39].

In the bioenergetic assay on SK-Hep1 cells (Figure 6), OGE above $200 \mu \mathrm{g} / \mathrm{mL}$ significantly decreased ECAR of malignant HCC cells, whereas OCR was significantly decreased only above 600 $\mu \mathrm{g} / \mathrm{mL}$. In Western blot, CDK4 level decreased with increasing concentration of OGE treatment in the HCC cells. Further evidence of change in glycolysis was found in the decrease of 6-phosphofructo-2kinase/fructose-2,6-biphosphatase 3 (PFKFB3) in HCC cells (data not shown), which is an allosteric activator of 6-phosphofructokinase-1 (PFK-1), a glycolysis stimulator. These findings suggest that the decreased cell viability of HCC cells by OGE treatment may be correlated with the inhibition of aerobic glycolysis. Similarly, a paper has shown that genistein, a natural isoflavone, induced HCC cell apoptosis by directly suppressing aerobic glycolysis [49]. However, since tumor weight from mice injected with Mahlavu cells significantly decreased after OGE treatment (Figure 7), we suggest that OGE treatment may cause tumor growth decrease by modulation of ERK signaling pathway and aerobic glycolysis and increasing cell apoptosis. 


\section{Acknowledgements}

This work was supported by grants from the Ministry of Science and Technology, Republic of China (MOST 106-2320-B-039-022and MOST 1072320-B-039-025-MY3), as well as in part by Taiwan Ministry of Health and Welfare Clinical Trial and Research Center of Excellence (MOHW106-TDU-B212-113004 and MOHW-10965).

\section{Competing Interests}

The authors have declared that no competing interest exists.

\section{References}

1. Bruix J, Sherman M. AASLD Practice Guideline. Management of hepatocellular carcinoma: an update. Hepatology. 2010;1-35.

2. El-Serag HB, Marrero JA, Rudolph L, et al. Diagnosis and treatment of hepatocellular carcinoma. Gastroenterology. 2008; 134:1752-1763.

3. Shariff MI, Cox IJ, Gomaa AI, et al. Taylor-Robinson SD. Hepatocellular carcinoma: current trends in worldwide epidemiology, risk factors, diagnosis and therapeutics. Expert Rev Gastroenterol Hepatol. 2009; 3:353-367.

4. Jemal A, Bray F, Center MM, et al. Global cancer statistics. CA Cancer J Clin. 2011; 61: 69-90.

5. Wong $\mathrm{R}$ and Frenette C: Updates in the Management of Hepatocellular Carcinoma. Gastroenterol Hepatol. 2011; 7: 16-24.

6. Abdel-Rahman O, Abdel-Wahab M, Shaker M, et al. Sorafenib versus capecitabine in the management of advanced hepatocellular carcinoma. Med Oncol. 2013; 30: 655 .

7. Zhu YJ, Zheng B, Wang HY, et al. New knowledge of the mechanisms of sorafenib resistance in liver cancer. Acta Pharmacol Sin. 2017; 38(5):614-622.

8. Llovet JM, Ricci S, Mazzaferro V, et al. SHARP Investigators Study Group. Sorafenib in advanced hepatocellular carcinoma. N Engl J Med. 2008; 359: 37890

9. Cheng AL, Kang YK, Chen Z, et al. Efficacy and safety of sorafenib in patients in the Asia-Pacific region with advanced hepatocellular carcinoma: a phase III randomised, double-blind, placebo-controlled trial. Lancet Oncol. 2009; 10: 25 34

10. George, S. and Chaturvedi, P. A comparative study of the antioxidant properties of two different species of Ocimum of southern Africa on alcohol-induced oxidative stress. J. Med. Food. 2009; 12: 1154-1158.

11. Li PC, Chiu YW, Lin YM. et al. Herbal Supplement Ameliorates Cardiac Hypertrophy in Rats with CCl4-Induced Liver Cirrhosis. Evid Based Complement Alternat Med. 2012; 2012(139045): 1-9.

12. Lee MJ, Chen HM, Tzang BS, et al. Ocimum gratissimum aqueous extract protects $\mathrm{H} 9 \mathrm{c} 2$ myocardiac cells from $\mathrm{H} 2 \mathrm{O} 2$-induced cell apoptosis through Akt signalling. Evid Based Complement Alternat Med. 2011; 2011(578060): 1-8.

13. Chiu CC, Huang CY, Chen TY, et al. Beneficial Effects of Ocimum gratissimum Aqueous Extract on Rats with CCl4-Induced Acute Liver Injury. Evid Based Complement Alternat Med. 2012; 2012(7367520): 1-9.

14. Chang HC, Chiu YW, Lin YM, et al. Herbal supplement attenuation of cardiac fibrosis in rats with CCl4-induced liver cirrhosis. Chin. J. Physiol. 2014; 57: 41-47.

15. Chiu YW, Chao PY, Tsai CC, et al. Ocimum gratissimum is Effective in Prevention against Liver Fibrosis In Vivo and In Vitro. Am J Chin Med, 2014; 42: 833-852.

16. Chen YH, Chiu YW, Shyu JC, et al. Protective Effects of Ocimum gratissimum Polyphenol Extract on Carbon Tetrachloride-Induced Liver Fibrosis in Rats. Chin J Physiol, 2015; 58: 33-63

17. Chao PY, Lin JA, Ting WJ, et al. Ocimum gratissmum aqueous extract reduces plasma lipid in hypercholesterol-fed hamsters. Int J Med Sci. 2016; 13(11):819-824.

18. Chao PY, Lin JA, Ye JC, et al. Attenuation of Oxidative Stress-Induced Cell Apoptosis in Schwann RSC96 Cells by Ocimum Gratissimum Aqueous Extract. Int J Med Sci. 2017;14(8):764-771

19. Chao PY, Chiang TI, Chang IC, et al. Amelioration of estrogen-deficiency-induced obesity by Ocimum gratissimum. Int J Med Sci. 2017; 14(9): 896-901.

20. Lin $\mathrm{CC}$, Lin JK, Chang $\mathrm{CH}$. Evaluation of hepatoprotective effects of "Chhit-Chan-Than" from Taiwan. Pharm. Biol. 1995; 33: 139-143.

21. Aziba PI., Bass D and Elegbe Y. Pharmacological investigation of Ocimum gratissimum in rodents. Phytother. Res. 1999; 13: 427-429.

22. Ilori M, Sheteolu AO, Omonigbehin EA. et al. Antidiarrhoeal activities of Ocimum gratissimum (Lamiaceae). J. Diarrhoeal Dis. Res. 1996; 14: 283-285.

23. Ayisi NK. and Nyadedzor C. Comparative in vitro effects of AZT and extracts of Ocimum gratissimum, Ficus polita, Clausena anisata, Alchornea cordifolia, and Elaeophorbia drupifera against HIV-1 and HIV-2 infections. Antiviral Res. 2003; 58: 25-33.

24. Aguiyi JC, Obi CI, Gang SS, et al. Hypoglycaemic activity of Ocimum gratissimum in rats. Fitoterapia. 2000; 71: 444-446.

25. Casanova LM, da Silva D, Sola-Penna M, et al. Identification of chicoric acid as a hypoglycemic agent from Ocimum gratissimum leaf extract in a biomonitoring in vivo study. Fitoterapia. 2014; 93:132-141.
26. Atal CK, Sharma ML, Kaul A. et al. Immunomodulating agents of plant origin. I: Preliminary screening. J. Ethnopharmacol. 1986; 18: 133-141.

27. Chen HM, Lee MJ, Kuo CY, et al. Ocimum gratissimum Aqueous Extract Induces Apoptotic Signalling in Lung Adenocarcinoma Cell A549. Evid Based Complement Alternat Med. 2011; 2011: pii: 739093.

28. Lin CC, Chao PY, Shen CY, et al. Novel Target Genes Responsive to Apoptotic Activity by Ocimum gratissimum in Human Osteosarcoma Cells. Am J Chin Med. 2014; 42: 743-767.

29. Xia M, Yu H, Gu S, et al. p62/SQSTM1 is involved in cisplatin resistance in human ovarian cancer cells via the Keap1-Nrf2-ARE system. Int J Oncol. 2014; 45: 2341-2348.

30. Halatsch ME, Löw S, Mursch K, et al. Candidate genes for sensitivity and resistance of human glioblastoma multiforme cell lines to erlotinib. J Neurosurg. 2009; 111(2): 211-218.

31. Nangia-Makker $\mathrm{P}, \mathrm{Raz} \mathrm{T}$, Tait $\mathrm{L}$, et al. Ocimum gratissimum retards breast cancer growth and progression and is a natural inhibitor of matrix metalloproteases. Cancer Biol Ther. 2013; 14: 417-227.

32. Ekunwe SI, Hall SM, Luo X, et al. Fractionated Ocimum gratissimum leaf extract inhibit prostate cancer (PC3 $\cdot \mathrm{AR})$ cells growth by reducing androgen receptor and survivin levels. J Health Care Poor Underserved. 2013; 24(4 Suppl): 61-69.

33. Aden DP, Fogel A, Plotkin S, et al. Controlled synthesis of HBsAg in a differentiated human liver carcinoma-derived cell line. Nature 1979; 282: 615-616.

34. Chang C, Lin Y, O-Lee TW, et al. Induction of plasma protein secretion in a newly established human hepatoma cell line.Mol. Cell. Biol. 1983; 3: 11331137.

35. Chiang PC, Lin SC, Pan SL, et al. Antroquinonol displays anticancer potential against human hepatocellular carcinoma cells: a crucial role of AMPK and mTOR pathways. Biochem Pharmacol. 2010; 79(2): 162-171.

36. Kounelakis MG, Zervakis ME, Giakos GC, et al. On the relevance of glycolysis process on brain gliomas. IEEE J Biomed Health Inform. 2013; 17(1): 128-135.

37. Tseng PL, Wu WH, Hu TH, et al. Decreased succinate dehydrogenase B in human hepatocellular carcinoma accelerates tumor malignancy by inducing the Warburg effect. Sci Rep. 2018; 8(1): 3081.

38. Lopez-Mejia IC, Lagarrigue S, Giralt A, et al. CDK4 Phosphorylates AMPKa2 to Inhibit Its Activity and Repress Fatty Acid Oxidation. Mol Cell. 2017; 68(2): 336-349.

39. Yuan P1, Meng L, Wang N. SOX12 upregulation is associated with metastasis of hepatocellular carcinoma and increases CDK4 and IGF2BP1 expression. Eur Rev Med Pharmacol Sci. 2017; 21(17):3821-3826.

40. Tsai JH, Liu JY. Pharmacological Studies on the Aqueous Leave Extract of Ocimum Gratissimum L. Adaptive Med. 2017; 9(1): 23-27.

41. Lee SH, Kim HS, Park WS, et al. Non-small cell lung cancers frequently express phosphorylated Akt; an immunohistochemical study. APMIS.2002; 110: 587-592.

42. Schmitz KJ, Wohlschlaeger J, Lang H, et al. Baba HA.Activation of the ERK and AKT signalling pathway predicts poor prognosis in hepatocellular carcinoma and ERK activation in cancer tissue is associated with hepatitis C virus infection. J Hepatol. 2008; 48(1):83-90.

43. Chen HM, Lee MJ, Kuo CY, et al. Ocimum gratissimum Aqueous Extract Induces Apoptotic Signalling in Lung Adenocarcinoma Cell A549. Evid Based Complement Alternat Med. 2011; 2011. pii: 739093

44. Yang W, Lu Z. Nuclear PKM2 regulates the Warburg effect. Cell Cycle. 2013; 12(19): 3154-3158.

45. Ganapathy-Kanniappan S, Geschwind JF. Tumor glycolysis as a target for cancer therapy: progress and prospects. Mol Cancer. 2013; 12:152.

46. Lu CW, Lin SC, Chen KF, et al. Induction of pyruvate dehydrogenase kinase-3 by hypoxia-inducible factor- 1 promotes metabolic switch and drug resistance. J Biol Chem. 2008; 283(42):28106-28114.

47. Fanciulli M, Bruno T, Giovannelli A, et al. Energy metabolism of human LoVo colon carcinoma cells: correlation to drug resistance and influence of lonidamine. Clin Cancer Res. 2000; 6(4):1590-1597.

48. Kounelakis MG, Zervakis ME, Giakos GC, et al. On the relevance of glycolysis process on brain gliomas. IEEE J Biomed Health Inform. 2013; 17(1):128-135.

49. Li S, Li J, Dai W, et al. Genistein suppresses aerobic glycolysis and induces hepatocellular carcinoma cell death. Br J Cancer. 2017; 117(10):1518-1528. 